\title{
Sports or physical activity management: global intervention model Gestión del deporte o la actividad física: modelo de intervención global
}

Daniel Carranza-Bautista

Universidad Autónoma de Nuevo León (México)

\begin{abstract}
Sports or physical activity management is a concept that is maturing in the world but relatively new in Latin America with some relevance in recent years, the positive assessment of sport as a means to achieve social goals in the public sector and the opportunity it represents. This work focuses on literary analysis to determine a model that describes the dimension in relation to sports management or physical activities in a conceptual scheme uses the nature of a qualitative origin research that applies methods such as historical-logical, analysis- synthesis and modeling techniques, which result in a series of combinations between relationships of components and elements to conceive a global intervention model in sports management or physical activities. In conclusion, the model shows innovative approaches and proposals that can be considered as new lines of research in this disciplinary area.
\end{abstract}

Key Words: sports management, physical activity management, management models, management intervention, sports manager.

Resumen. La gestión de deportes o actividad física es un concepto que está madurando en el mundo, pero relativamente nuevo en América Latina con cierta relevancia en los últimos años, la evaluación positiva del deporte como un medio para lograr fines sociales en el sector público y la oportunidad que representa. Este trabajo se enfoca en el análisis literario para determinar un modelo que describa la dimensión en relación con la gestión deportiva o las actividades físicas en un esquema conceptual, para esto, se utiliza la naturaleza de una investigación cualitativa que aplica métodos como el histórico-lógico, análisis-síntesis, y técnicas de modelado, que dan como resultado una serie de combinaciones entre las relaciones de componentes y elementos para concebir un modelo de intervención global en el manejo deportivo o de las actividades físicas. En conclusión, el modelo muestra enfoques y propuestas innovadoras que pueden considerarse como nuevas líneas de investigación en esta área disciplinaria.

Palabras clave: gestión deportiva, gestión de actividades físicas, modelos de gestión, intervención de la gestión, gestor deportivo.

\section{Introducction}

Current sports management seeks to consolidate itself as an academic, scientific and professional area in Latin America, its intervention in the professional field requires a theoretical operational approach of specialization according to the level and type of organization, area or scope of action within the structure of a sports system. At present, this intervention is based on the integration of a framework of multiple scientific theories ranging from the classics established by Taylor, Fayol and their successors, quantitative and decisional theories, systems or situational theories, to current theories with business approaches. management styles, business excellence approaches or operational approaches (Rial, 2014).

By considering management as an executing action that presents a driving initiative and mobilization of efforts in search of satisfying the needs or problems that arise in a given area, it can be deduced that the task performed by sports management is more complex From what it usually seems, it is generally composed of a large number of activities that require extensive knowledge in their exercise and skills that go beyond ordinary work. Its intervention lies in multiple areas and environments that demand professionals with diverse skills, competencies and developed abilities. This is due to its nature as it has an unusual versatility as a disciplinary area, in its actions it integrates a wide variety of elements, disciplines and sub disciplines based on the needs of management in the process of achieving the goals, goals and the objectives set in the different contexts that it applies (Barrios, 2018; Jáuregui, Enríquez, Uribe \& Valenzuela, 2018;

Fecha recepción: 24-05-20. Fecha de aceptación: 22-09-20

Daniel Carranza-Bautista

carranzabd@hotmail.com

\section{Rial, 2014; Sancho, 2013).}

On the other hand, conceptually, management in the field of physical activity requires clarifying its intervention scheme together with sports management and considering the form required to mobilize the different efforts depending on the purpose. In this exercise, the means that facilitate their actions to achieve the objectives set out as part of the needs of organizations that lack or integrate a structured system in the context of physical or sports activities services must be identified with certainty. Management is the coordination of all aspects such as planning, organization and control, both of the behavior and of the activities of the employees, so that everything together works as an integrated system. " (Ramos et al., 2015). Although it is true that the administrative process is identified with management, the foregoing hardly exposes the integration of a few elements that affect the management of a structured sports system and the physical activities that comprise it, so it is necessary to clarify in greater extent which means the intervention of the management of physical or sports activities.

\section{Management dynamics in the context of physical or sports activities}

The dynamics of management starts from a primary basic approach for its understanding, as most of the proceedings are focused on the principle of the mobilization or mobility of the various resources in a timely manner. In the operational reality of the management of physical or sports activities, there are different components and elements that make up a scheme, which determines the mobilization of the different resources or elements used as means to achieve the goals, objectives, purposes or ends desired. These components articulate a very particular dynamic mechanism for the management of physical or sports activities services that 
attends to the needs of the environment, which generates a positive effect when it is efficient and effective in satisfying the needs or negative in the absence of respect the natural process of management in its mission to comply with a demand. This proposed scheme can be considered as the dynamics of the management of physical or sports activities.

To understand the dynamic concept of management, it is necessary to speak as the first component of the intervention scheme, which is made up of multiple elements identified in three large groups: 1) the planning elements that visualize the needs of the context, define the goals and objectives that are required to be achieved in management from a vision to mobilize resources at different levels of management according to their hierarchy, 2) the means that are required according to the level of complexity to achieve the goals or objectives in a sports system or physical activities structured and 3) the differentiating elements of the sports or physical activity system that are articulated and made up from a macro environment to the smallest operational structure to carry out an activity or task in search of a goal or objective. This conceptualization is proposed based on the elements provided by various authors (Blanco, 2014; Mendoza, 2016; Olarte, 2018; Ortiz et al, 2015; Rial, 2015; Sancho, 2013).

Another component of the management dynamics is characterized by triggering or activating the management of physical or sports activities in the intervention scheme, where multiple internal and external factors to the organizations are identified that directly or indirectly affect the mobilization of the resources to achieve the desired goals, objectives or purposes, which can be proposed by the same entity or adopted in a way conditioned by the environment in which an organization operates, in this sense authors such as Celma (2004), Bossio (2006), Grimaldi and Sánchez (2019), Grimaldi and Ferrer (2016), Mendoza (2016), Olarte (2018), Sancho (2013) and Sánchez et al., (2014), highlight factors such as: social and political dynamics in the first instance, cultural and economic environment or region, globalization and its process, new market trends and the change that is generated, business aspects that refer to innovation, competitiveness, sustains it reliability, evolution, sustainability, quality of services and their profitability, several of which represent new trends of the early 21 st century. These multiple factors can be considered as the indirect or direct forces that mobilize the dynamic intervention of management in the field of organizations that provide services for physical or sports activities.

Based on the above, the following component is located at the starting point of the requirements of the entities or organizations that provide services in physical or sports activities, which focuses on the needs of the demands of the environment internal or external forces that generate the dynamics of managing from the position of the elements that visualize the scope and complexity of the management on the aims pursued, which leads to integrate the crystallized guidelines into the ends, purposes, goals and objectives as components of the management dynamics to provide the direction and standards that are necessary to achieve to satisfy the problems, demands and needs of the different levels in which the fields of action and their environment are found.
The dynamics of the management of physical or sports activities from the perspective of this work consider two more essential components, one is the management process which refers to this, such as the natural temporality that represents the intention to generate a regulatory, transforming effect or change to satisfy a demand or requirement through the integration of a set of elements and mobilization of resources, this component is located in the starting point of the management that are the requirements and the achievement of what is planned on the main guidelines where it is important to consider what is established by Vélez et al., (2018), who, affirm that «if these processes are not executed effectively, it is possible that the objectives are not adequately aligned, which could cause problems to achieve them». In this sense, it should be noted that the management process integrates elements based on the purposes pursued, such as: the type of service, the resources, the methodology or techniques that are applied, procedures, internal execution policies, areas functional tasks or activities to be carried out, projects, problems that are addressed, etc.

The last component is the time that the management lasts in the intervention scheme of the management of physical or sports activities and has to do with the consideration of the complexity of the tasks, the temporal requirements in the operation of the management, the capacities of the organization, the multiple factors that affect the different levels that make up the intervention scheme of the management of physical or sports activities (Camy \& Robinson, 2007; Tamayo et al., 2015).

\section{The role of the physical and sports activity manager}

The work context of the sports or physical activity manager demands professionals with a full idea of the operational schemes and the role to be performed as a specialist in the area, so that they can apply the knowledge and their skills to integrate the elements that contribute to efficiently favor management processes from any level of the organization's structure, one of the main challenges is to integrate the key elements and areas that are associated in a multidisciplinary way to achieve the goals and objectives set.

For modern managers in the field of physical or sporting activity to achieve the expected results, it implies understanding in the first instance the global context of management, the dynamics they play within that scheme and later, the way in which they have to intervene based on the real demands of the services demanded by society, in this sense Aguilar and Guerra (2015) and Pereira (2016) argue that the demands of the labor market of managers of physical or sports activities are subject to identifying the constant changes in the environment in relation to the dynamics or versatility required by the different positions, positions and functions, in addition to considering the strategic areas that are integrated or that operate at the different hierarchical levels of the structure of the sports system, organizations, its fields of action and the different services in the professional field of the manager of physical or sports activities, is it should be noted that his intervention focuses on the needs that are generated in a social reality of the practice of sport, physical activity, the services that are required to be offered and the 
different disciplines that make up an organizational structure where their participation can lie in high, middle or low managers, a situation that will depend on the hierarchical or complexity levels of the organization to which it is integrated, while considering that there are other alternative needs that require a more specialized intervention from the manager with a transversal and strategic approach (BOE, 2014; Sancho, 2013: Rial, 2015)

The relationship of the sports or physical activities manager on the areas in which he intervenes are predetermined by strategic functions of command, integration and mobilization of resources to coordinate efficiently and effectively the different groups that converge or elements that make up the areas, to support what favors the needs of the plans, projects, programs and the forces that trigger the operation of an organization, a system or structure in a certain field of action. Some of these most common areas are: marketing, finance, infrastructure management, human resources, communication and the use of technologies; and the positions he occupies range from general directions, management, coordination, heads of technical and operational areas, logistics of activities and the organization of sporting events (Celma, 2004; Ramírez, 2017; Rial, 2014; Tafalla, 2004).

From this approach, its functions go beyond applying only the administrative process, since it deals with multiple processes and the management of systems and models, with capacities such as: transforming environments, disciplinary integration, structuring projects, creating and implementing programs. , integrate and operate new technologies, design strategic and operational plans, generate internal policies and contribute to the construction of public policies, mobilize resources efficiently and effectively, in addition to understanding the dynamics of management itself as a means to achieve the goals and objectives.

\section{Structure and organization of the global sports system}

For Tamayo et al. (2015) «in the international context, sports activity increases its importance; the increase in commercialization, competitiveness, the number of participating countries and the use of increasingly innovative technologies in order to increase sports performance». This perspective places sport as a central axis that integrates new elements and factors that require greater attention within the management of a global sports structure or system; However, it is necessary to recognize that over time the sports system at the international level has evolved in different ways, which results in the consideration that: «sport in globalization is a historical discontinuity that is specified as bodily practice, work, business, under the specificity of the social system in which it is generated «(Mendoza, 2016).

The sports system in its complex network integrates elements and public or private organizations through various lines of action or areas of action based on the different needs of the management of sports activities. For Bossio and Alexander (2006) «sport and physical activity, being the object of social planning, demands more than ever the knowledge of its social reality, of the interrelationships between the main variables of the sports system», while Guzmán (2006 ) states that a sports system is understood as the «set of all those elements related to each other, according to an order, and that contribute to the development of sport in all its manifestations.»

Another aspect that must be considered is that sports management as a disciplinary area finds its operation diversified through the sports system of each nation, from a structure that ranges from the simplest to the most complex, Camps (2014) in an analysis of the sports structures, refers to the organization of sports in several countries such as Italy, France, Great Britain, Denmark, Germany, Switzerland and the United States, where it describes structures with similar management models, which present some variants in their sports system in the integration of clubs, associations, federations, commissions, sports ministries and confederations, most of them aligned by a governing body and by the National Olympic Committee of each country whose main function is to regulate the interests of the federations.

As can be seen, the organization of the sports system in most countries has similar characteristics, it is made up of organizations that are recognized by international organizations who regulate the way of governing in the different structures and organizations in the context of the offer of the practice of physical activities and sports competitions in each country (see table 1).

Based on the foregoing, the management fulfills three very significant functions, the first one that pertains to the work of managing and regulating sports competition in the structured system for the development of high-performance or elite athletes as defined as sports management; the second,

Table 1

\begin{tabular}{|c|c|c|}
\hline Central axis & Elements that integrate it. & Function \\
\hline $\begin{array}{l}\text { The structure of the World Sports } \\
\text { Organization }\end{array}$ & $\begin{array}{l}\text { International Olympic Committee, International Federations. World Health } \\
\text { Organization, European Community, UNESCO. }\end{array}$ & $\begin{array}{l}\text { Promotion, organization, standardization, monitoring and development of physical and } \\
\text { sports activities at international level, environmental management, management of } \\
\text { structural change and governance according to the needs of the region. }\end{array}$ \\
\hline $\begin{array}{l}\text { Transnational companies or } \\
\text { organizations }\end{array}$ & $\begin{array}{l}\text { Companies affiliated with global organizations, independent companies or } \\
\text { private concessions, companies of goods and services of physical activities and } \\
\text { sports, companies that engage in the practice of physical activities or sports. }\end{array}$ & $\begin{array}{l}\text { They sponsor the sporting event, athletes-competitors. They place goods and services } \\
\text { associated with the sport, spread the event through the purchase of rights. }\end{array}$ \\
\hline $\begin{array}{l}\text { Federations, associations and } \\
\text { National Committees, associations }\end{array}$ & $\begin{array}{l}\text { Federations and associations of each sports discipline, National Sports } \\
\text { Organizations, We organize national sports leaders. }\end{array}$ & $\begin{array}{l}\text { Regulation of sport and national physical education, execute the country's sports } \\
\text { policies, representation before public authorities and official bodies, representation of } \\
\text { athletes, organize practice and sports competitions. }\end{array}$ \\
\hline Regional organizations & $\begin{array}{l}\text { Organization of the state sport, organization of the regional sport, municipal or } \\
\text { town hall sport and educational and academic sector. }\end{array}$ & $\begin{array}{l}\text { Organization of physical and sports activities of a public nature and in some cases } \\
\text { private, research management at the graduate level. }\end{array}$ \\
\hline Clubs or Professional Teams & Representatives in the leagues of each sports discipline. & $\begin{array}{l}\text { Independent organizations with administrative functioning, Integrate shareholders, } \\
\text { partners and committees for the regulation of associations and associate with federations. }\end{array}$ \\
\hline $\begin{array}{l}\text { Professionals and human resources } \\
\text { involved }\end{array}$ & Technical staff, athletes, sports managers, support staff, volunteering. & Participate in the organization of local, regional, national and global events \\
\hline Athletes & Competitors and athletes. & $\begin{array}{l}\text { Participate in the competitions, work on a multidisciplinary preparation (physical, } \\
\text { technical, tactical, strategic and psychological). }\end{array}$ \\
\hline Public and practitioners & Consumers and practitioners. & $\begin{array}{l}\text { Appreciate sport, Consume, potential buyer of goods and services, practice physical or } \\
\text { sports activities in leisure time by bone or recreation. }\end{array}$ \\
\hline
\end{tabular}


which refers to the management of social responsibility for demographic, cultural, political, social and governmental demands regarding the needs to practice physical activities for the benefit of the common good of the environment where it is managed; and the third, integrates a management system that manages to articulate in an orderly manner the dual development of the two aforementioned functions.

From this vision, a current reality is observed where management integrates a system that fulfills a dual function that must be recognized and clarified, it should be noted that in its two aspects it fulfills the same function that is to manage the practice of physical activities and sports with similar means, techniques and tools, to highlight that different methods are required, one that develops sports competition from its inception to the culmination of an elite sports career, and the other multidimensional as it requires favoring social demands, economic, political and cultural of each country or region

Both methods require adapting to the different management forces among which are mainly identified: the services that are required to be offered, the competitiveness of the organizations, the quality of the products and services, the technological evolution, and the self-sustainability within the system. that is operated.

On the other hand, sports management or physical activities from a social responsibility must cover the needs of the system structure in any context or environment that is performed, has the obligation to guarantee the practice of physical and sports activities in harmony with the economy of the region, culture, political forces and social demand. Management in this disciplinary area demands the integration of new technologies, betting on strategic communication to achieve objectives that must be a priority, favoring business profitability, competitiveness of organizations through supply and demand based on the needs to manage the practice of physical or sports activities to establish a link of social responsibility and satisfy the users in the service (Nuviala et al., 2020; Pascual et al., 2019; Souto et al, 2019) .

In consideration of the above arguments, on the one hand, some characteristics on which a sports system must be managed in a general context stand out:

- The pertinent regulation through the alignment, unification of policies, laws and regulations that support the flow of sports competitions in an ascending linear system.

- The flow of sports development providing the opportunity for any athlete to have growth.

- The organic articulation referring to the interlocking organizations as the articulation of links in one, interaction, communication and functional connection of each of the entities and organizations.

A sports system is not only structured from its global conception in attending and managing sports competition, to be successful, its intention must lie in interacting with the public, social and business sectors from a strategic perspective, without leaving aside its essence which lies in the structure of the Olympic Model of sports competition (Olarte, 2018; Pereira, 2016; Tamayo et al., 2015). From the aforementioned, a system of physical or sports activities can be defined as an organizational structure that facilitates the operation of the competition and practice of physical activities. Integrated by various entities that interact and articulate with each other, in a permanent process that adjusts to the own management needs according to their geographical situation, region or country, to coordinate in a systematic and orderly way the tasks or activities depending on the dynamics, culture, policies and regulations in each social area involved.

\section{Conceptual models in the management of physical and sports activities}

Grant Thornton Corporation (2017) establishes that a management model «comes to be the different systems of carrying out the development and administration of an organizational structure.» In the disciplinary area of sports management, a management model is a conceptual tool that generally uses a well-argued scheme as an indication to refer to an organizational structure with criteria, principles and norms that project an idea «they articulate different processes in a systematic way in direction to an approach...» (Carranza, 2018); They allow clarifying leadership and establishing governance through the implementation of a culture or focus with a purpose, in organizations that provide services in physical or sports activities, their conceptualization focuses on establishing and regulating the criteria that guide operational activities, management tactics or strategies that allow achieving goals, objectives.

From a global vision, a sports or physical activity management model must fulfill the purpose of being a frame of reference that representatively addresses the context with a broad and orderly sense, and in turn shows unification in its criteria towards a global reality. of global governance practices that are successful in promoting a culture in pursuit of the favorable development of physical or sports activities (Bustamante et al., 2019; Olarte, 2018), however, it is necessary to consider that there are countries or regions whose characteristics development are very complex, where economic, political, cultural and infrastructure factors play a transcendental role for the adoption or implementation of a management model based on international public policies. This perspective opens the opportunity to make an analysis of more technical management intervention models that provide an adjustable and not so complex scheme for an environment such as the transversal model of Paris cited by Rial (2014) that integrates multiple interacting elements, but at the same time distinguishes a clear transversal division on the management of physical and sports activities (see figure 1).

On the other hand, it is necessary to consider that there are public or private organizations that provide services in the physical or sports activities sector that implement management models empirically extrapolated or adapted from other disciplinary areas, in this sense most of the managers or administrators with academic training show knowledge about how to manage the organization in a systematic way through this pattern, while another sector of improvised professionals start from experience, their intuition and deduction from the problems and challenges that are presented to try to manage successful organization (Celma 2004; Pereira, 2016). 
For Jáuregui et al., (2018) «The versatility and continuous evolution of the sports sector make necessary a flexible and open management model in order to adapt to the rapid changes that occur». This implies that one of the characteristics of a model in the field of physical and sporting activity is that it manages to adjust to the social and institutional reality of the context in which it is used. In another sense, from the perspective of experiences in the business sector in the management of physical or sports activities, the new management models must comply with a vision towards new trends with more versatile, transversal and independent contributions that integrate models with approaches towards trends such as sustainability, the self-sustainability of public or private sports organizations, innovation in the integration of new technologies, competitiveness as a way of evolving, in addition to considering social responsibility as an essential element to enter into communion with the social environment that interacts (Alvarez, 2017; Gallardo \& Lozano, 2006).

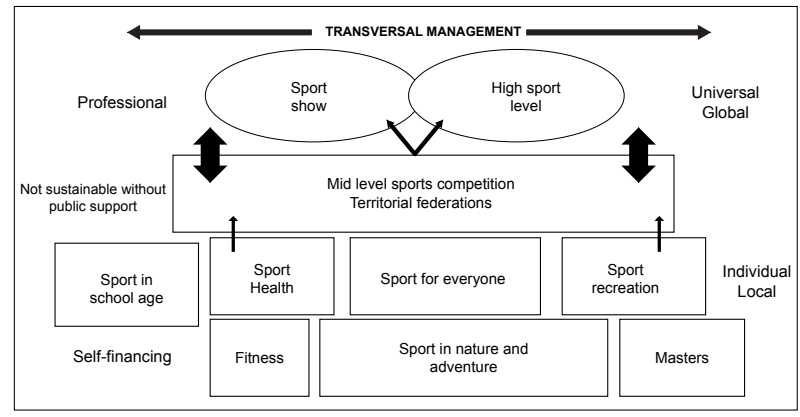

Figure 1. Multifactorial grouping management model.

Note. The model outsources sports services and forms of organization of physical and sports activities, in a structure that groups sports action areas horizontally and involves public, private and third sector organizations. Transversal management model of sport XXI century (Paris, 2003), cited in Evolution of the management of sport in the Spanish territory: synthesis, by BM Rial, 2014, Challenges: new trends in physical education, sport and recreation, 26, p .136.

\section{Spheres of action of sports management or physical activities}

The fields of action of sports management or physical activities are undoubtedly within the organizations that provide services in these two disciplinary areas and can be of a public or private nature, their close connection with society is the main trigger of the diversification of supply and demand from the main interests of the population. Clubs, federations, gyms, sports units, universities, educational institutions, municipal sports centers contribute to the integral development of the maturation processes of in specific contexts in the fields of action who must seriously consider the main indicators of consumption or segments of interest (Celma, 2004; López, Villamón and Sanz, 2019; Mendoza, 2016; Pereira, Bartoll, \& Domingo 2014; 2016; Navarro et al., 2020; De la Cámara et al., 2020).

There are multiple areas of management action that a manager must recognize in order to be able to consider the needs demanded by the environments in relation to practice and service (see figure 2). Management and its relationship with the field of action is aimed at developing a physical or sporting activity that is distinguished by showing a certain approach or type of service, focused on satisfying certain cultural, political or economic characteristics of the environment in which it is identified, to take into account at all times the particular interests of the organizations that provide the service. In this sense, it can be said that a field of action of the management of physical or sports activities is a context that allows management to interact and perform as a discipline in order to satisfy the needs in terms of the way a company operates. structure or a system, which addresses the demands of multiple fields or branches with a specific focus and type of service that compete to satisfy the demands of the practice of a geographical area.

While it is true «management in the sports field falls a lot into acceptance controversies, since there is no general agreement of what is required to be a professional in sports management» (Pérez, 2017), on the other hand, there are some areas of opportunity to contextualize the needs of management in the structures of sport and physical activity, the levels at which it operates and its complexity, so it is necessary to provide more elements that help to clarify the scope of action of sports management or physical activities from a perspective that encompasses the general to the more specific, with the intention of locating more precisely the role and role it plays within a scheme of intervention opportunities. From this perspective, it is appreciated that it is necessary to have a conceptual model from a global perspective of the performance of sports management or physical activities, which I clarified and graphically explained its intervention in the different areas according to their level of complexity. For this reason, the objective of this work is focused on conceptualizing a model of intervention for the management and manager of physical or sports activities, through a scheme that structures and integrates features of knowledge to express a clear idea about its scope of action, as well as its different levels, in order to understand and visualize the dynamics of modern management in this disciplinary field.

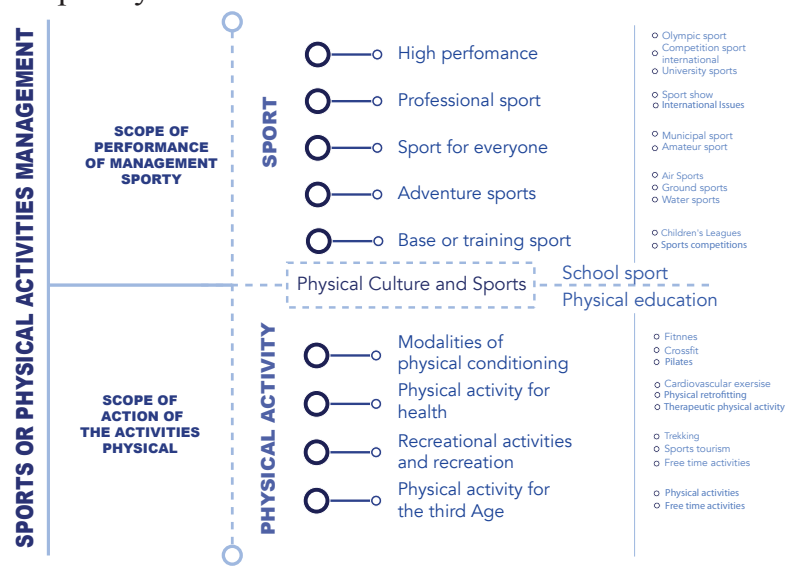

Figure 2. Fields of action of sports management or physical activities

Note: scheme considers the division into two general spheres of management 1) physical activities where, as an example, it considers the modalities of physical conditioning, physical activity for health, leisure and recreation activities and activities for the elderly, 2) the sports that consider high performance sports, professional sports, sports for everyone, adventure sports, basic or educational sports. Both present different approaches that can determine the type of service and the characteristics of the management, 3) It is worth highlighting Physica Culture and Sports as the central part that emerges from the school environment by integrating Culture and Sports as the central part that emerges from the school environment by integrating
physical education and sports as formative elements in the generation of a culture towards the physical education and sports as formative elements in the generation of a culture towards the practice of physical or sports activities in society. It is necessary to emphasize that the scheme classification, it only tries to place the reader in an approximation of what they can

\section{Methodology}

The research design is of a post-structural and postmodern qualitative nature, «it postulates an uncertain, diversified and subjective reality which demands a plurality of reading» (Anadón, 2008). It focuses on responding through 
content analysis to the objectives and the problem raised, uses the available literature to follow structural patterns based on information that has been collected and processed based on key documents, from the literary review of publications of scientific nature and protected works related to the management of physical and sports activities through indirect observation. "It considers three basic aspects from the methodological point of view: the approach, the type of research and the theoretical construction of the process ...» (Gómez, 2011).

Applying the analysis-synthesis method, «It admits the separation by differentiating, the classification by grouping together and the union based on criteria. It starts from the complex to the simplest by mere inductive and deductive exercises» (Valbuena, 2018). With this analysis, the basic essential processes were identified, in addition to the main concepts related to the management of sports and physical activities; In this sense, we worked with documents, constructs and texts with significant contributions that refer to the object of study through synthesis, with the intention of extracting and interpreting the relevant information that contributes to understanding the main phenomena of management in relation to with the theme.

The historical-logical analysis method was used to provide basic foundations with a common sense in the construction of the theoretical framework from topics chronologically and in order of importance to give meaning to the research and thus be able to respond to the study problem. It determines facts and presents past antecedents to explain links and form conclusions that support the results of the present (Abreu, 2014).

It is based on modeling through the graphic representation of conceptual models that allowed to give support to the research in order to clarify some elements that made up the proposal of an intervention model in the global context of sports management or physical activities. With the intention of explaining reality through multiple solutions, the knowledge of the object of study in its natural environment was deepened, focusing on what is important in an abstract plane (Varela et al., 2014).

The Atlas.ti software was used to process the information. Version 8.1. Which is a powerful set of tools for the qualitative analysis of large bodies of textual data, on which the

Table 2

Codes, their relationship with citations and the number of co-occurrences between codes.

\begin{tabular}{llcccc}
\hline \# & Codes & $\begin{array}{c}\text { No. of citations } \\
\text { associated with } \\
\text { the Gr code }\end{array}$ & $\begin{array}{c}\% \text { That } \\
\text { Represents }\end{array}$ & $\begin{array}{c}\text { No. of co- } \\
\text { occurrences bet } \\
\text { ween codes }\end{array}$ & $\begin{array}{c}\text { \% That } \\
\text { Represents }\end{array}$ \\
\hline 1 & AA Areas of action & $\mathbf{1 1 0}$ & $\mathbf{1 2 . 9 6}$ & $\mathbf{2 8 3}$ & $\mathbf{1 0 . 9 2}$ \\
2 & IISM Areas that integrate sports management & 22 & 2.59 & 60 & 2.31 \\
3 & OE Organizational structure & 42 & 4.95 & 134 & 5.17 \\
4 & SMF Sports management forces & 38 & 4.48 & $\mathbf{2 4 1}$ & $\mathbf{9 . 3 0}$ \\
5 & MF Manager functions & $\mathbf{9 8}$ & $\mathbf{1 1 . 5 4}$ & $\mathbf{2 6 7}$ & $\mathbf{1 0 . 3 0}$ \\
6 & SMPA Sports Management or of physical activities. & 68 & 8.01 & 173 & 6.67 \\
7 & EM Environment management & 33 & 3.89 & 109 & 4.21 \\
8 & SM Strategic management & 69 & 8.13 & 204 & 7.87 \\
9 & MM Management models & 49 & 5.77 & 146 & 5.63 \\
10 & MO Management objectives & 52 & 6.12 & 149 & 5.75 \\
11 & SO Sports organizations & 55 & 6.48 & 182 & 6.02 \\
12 & PSMPA Process of Sports Management or of physical activities & $\mathbf{1 1 0}$ & $\mathbf{1 2 . 9 6}$ & $\mathbf{3 1 7}$ & $\mathbf{1 2 . 2 3}$ \\
13 & 67 & 7.89 & $\mathbf{2 2 1}$ & $\mathbf{8 . 5 3}$ \\
14 & SSS Sports services & 36 & 4.24 & 106 & 4.09 \\
\hline \multicolumn{2}{l}{ Total } & 849 & 100 & 2592 & 100 \\
\hline Note: The 14 main codes resulting from the logical merger that resulted from the analysis-synthesis method of
\end{tabular}

Note: The 14 main codes resulting from the logical merger that resulted from the analysis-synthesis method of the documents are shown. The relationship between the codes and the number of citations in which it is presented is presented, in addition to the percentage that each code represents based on the total number of incidences on the citations that were 849 , which are highlighted in bold the first three codes with higher incidence. The fourth column shows the number of co-occurrences between codes to highlight the five codes with the highest co-occurrences, their total which is 2592 and the percentage that it represents according to the total.

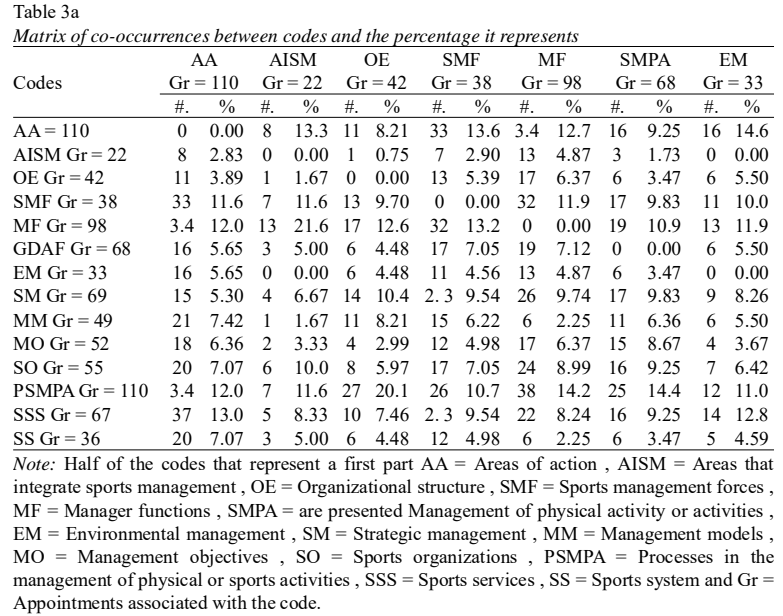

Table $3 \mathrm{~b}$

\begin{tabular}{|c|c|c|c|c|c|c|c|c|c|c|c|c|c|}
\hline \multirow[t]{2}{*}{ Codes } & \multicolumn{2}{|c|}{$\begin{array}{c}\mathrm{SM} \\
\mathrm{Gr}=69\end{array}$} & \multicolumn{2}{|c|}{$\begin{array}{c}\mathrm{MM} \\
\mathrm{Gr}=49\end{array}$} & $\begin{array}{c}\mathrm{MO} \\
\mathrm{Gr}=52\end{array}$ & \multicolumn{2}{|c|}{$\begin{array}{c}\mathrm{SO} \\
\mathrm{Gr}=55\end{array}$} & \multicolumn{2}{|c|}{$\begin{array}{c}\text { PSMPA } \\
\mathrm{Gr}=110\end{array}$} & \multicolumn{2}{|c|}{$\begin{array}{c}\text { SSS } \\
\mathrm{Gr}=67\end{array}$} & \multicolumn{2}{|c|}{$\begin{array}{c}\mathrm{SS} \\
\mathrm{Gr}=36\end{array}$} \\
\hline & \#. & $\%$ & \#. & $\%$ & \#. $\%$ & & $\%$ & \#. & & & $\%$ & \#. & $\%$ \\
\hline AISM Gr $=22$ & 15 & 7.35 & 21 & 14.3 & $18 \quad 12.0$ & 20 & 10.9 & 3.4 & 10.7 & 37 & 16.7 & 20 & 18.87 \\
\hline $\mathrm{OE} \mathrm{Gr}=42$ & 4 & 1.96 & 1 & 0.68 & 21.34 & 6 & 3.30 & 7 & 2.21 & 5 & 2.26 & 3 & 2.83 \\
\hline $\mathrm{SMF} \mathrm{Gr}=38$ & 14 & 6.86 & 11 & 7.53 & 42.68 & 8 & 4.40 & 27 & 8.52 & 10 & 4.52 & 6 & 5.66 \\
\hline $\mathrm{MF} \mathrm{Gr}=98$ & 2.3 & 11.2 & 15 & 10.27 & 128.05 & 17 & 9.34 & 26 & 8.20 & 2.3 & 10.4 & 12 & 11.32 \\
\hline $\mathrm{GDAF}$ Gr $=68$ & 26 & 12.7 & 6 & 4.11 & $17 \quad 11.4$ & 24 & 13.1 & 38 & 11.9 & 22 & 9.95 & 6 & 5.66 \\
\hline $\mathrm{EM} \mathrm{Gr}=33$ & 17 & 8.33 & 11 & 7.53 & $15 \quad 10.0$ & 16 & 8.79 & 25 & 7.89 & 16 & 7.24 & 6 & 5.66 \\
\hline $\mathrm{SM} \mathrm{Gr}=69$ & 9 & 4.41 & 6 & 4.11 & 42.68 & 7 & 3.85 & 12 & 3.79 & 14 & 6.33 & 5 & 4.72 \\
\hline $\mathrm{MM} \mathrm{Gr}=49$ & 0 & 0.00 & 14 & 9.59 & 138.72 & 14 & 7.69 & 31 & 9.78 & 17 & 7.69 & 7 & 6.60 \\
\hline $\mathrm{MO} \mathrm{Gr}=52$ & 14 & 6.86 & 0 & 0.00 & 128.05 & 7 & 3.85 & 22 & 6.94 & 17 & 7.69 & 3 & 2.83 \\
\hline $\mathrm{SO} \mathrm{Gr}=55$ & 13 & 6.37 & 12 & 8.22 & $\begin{array}{ll}0 & 0.00\end{array}$ & 12 & 6.59 & 22 & 6.94 & 11 & 4.98 & 7 & 6.60 \\
\hline PSMPA $\mathrm{Gr}=110$ & 14 & 6.86 & 7 & 4.79 & 128.05 & 0 & 0.00 & 29 & 9.15 & 14 & 6.33 & 8 & 7.55 \\
\hline SSS Gr $=67$ & 31 & 15.2 & 22 & 15.0 & 2214.7 & 29 & 15.9 & 0 & 0.00 & 28 & 12.6 & 16 & 15.09 \\
\hline $\mathrm{SS} \mathrm{Gr}=36$ & 17 & 8.33 & 17 & 11.6 & 117.38 & 14 & 7.69 & 28 & 8.83 & 0 & 0.00 & 7 & 6.60 \\
\hline $\mathrm{AA}=110$ & 7 & 3.43 & 3 & 2.05 & $\begin{array}{ll}7 & 4.70\end{array}$ & 8 & 4.40 & 16 & 5.05 & 7 & 3.17 & 0 & 0.00 \\
\hline
\end{tabular}

information was cited, organized, grouped, codified, managed and synthesized.

An exploratory qualitative analysis of 38 key documents related to the object of study was carried out through the literary review, the information was selected from the use of the historical-logical method and the analysis-synthesis, to be cited and coded in Atlas.ti 8.1. Starting from the problematic situation that provided a perspective to arrive at a conceptualization around the intervention of the management of physical or sports activities, a first phase was worked where 294 citations and 58 codes were identified. Later, in a second phase, the codes were merged on those that had the highest incidence as a result of the analysis of structural patterns indicated by the available literature until reaching 14 codes related to the object of study. In a third phase, a co-occurrence analysis was carried out to determine the total number of citations between codes and the percentage that each code represents, the total of co-occurrences between codes was determined and in the same way the percentage that each one represents (see table 2).

To identify the degree of relationship between codes, determine the level of association, which codes are part of another code, which codes are the cause of another code, property of another code or those codes 
Table 4

\begin{tabular}{|c|c|c|c|c|c|c|c|c|c|c|c|c|c|}
\hline Codes & $\begin{array}{c}\mathrm{AA} \\
\mathrm{Gr}=110\end{array}$ & $\begin{array}{c}\mathrm{AISM} \\
\mathrm{Gr}=22\end{array}$ & $\begin{array}{c}\mathrm{OE} \\
\mathrm{Gr}=42\end{array}$ & $\begin{array}{c}\text { SMF } \\
\mathrm{Gr}=38\end{array}$ & $\begin{array}{c}\mathrm{MF} \\
\mathrm{Gr}=98\end{array}$ & $\begin{array}{c}\text { SMPA } \\
\mathrm{Gr}=68\end{array}$ & $\begin{array}{c}\mathrm{EM} \\
\mathrm{Gr}=33\end{array}$ & $\begin{array}{c}\mathrm{SM} \\
\mathrm{Gr}=69\end{array}$ & $\begin{array}{c}\mathrm{MM} \\
\mathrm{Gr}=49\end{array}$ & $\begin{array}{c}\mathrm{MO} \\
\mathrm{Gr}=52\end{array}$ & $\begin{array}{c}\mathrm{SO} \\
\mathrm{Gr}=55\end{array}$ & $\begin{array}{c}\text { PSMPA } \\
\mathrm{Gr}=110\end{array}$ & $\begin{array}{c}\text { SSS } \\
\mathrm{Gr}=67\end{array}$ \\
\hline AISM Gr $=22$ & 8.08 & - & & & & & & & & & & & \\
\hline $\mathrm{OE} \mathrm{Gr}=42$ & 6.05 & 4.94 & - & & & & & & & & & & \\
\hline $\mathrm{SMF} \mathrm{Gr}=38$ & 12.68 & 7.29 & 7.55 & - & & & & & & & & & \\
\hline $\mathrm{MF} \mathrm{Gr}=98$ & 12.37 & 13.27 & 9.53 & 12.63 & - & & & & & & & & \\
\hline GDAF Gr $=68$ & 7.45 & 3.37 & 3.97 & 8.44 & 9.05 & - & & & & & & & \\
\hline $\mathrm{EM} \mathrm{Gr}=33$ & 2.83 & 0.00 & 4.99 & 7.33 & 8.40 & 4.49 & - & & & & & & \\
\hline $\mathrm{SM} \mathrm{Gr}=69$ & 3.63 & 4.31 & 8.66 & 10.41 & 11.24 & 9.08 & 6.33 & - & & & & & \\
\hline $\mathrm{MM} \mathrm{Gr}=49$ & 10.90 & 1.18 & 7.87 & 8.25 & 3.18 & 6.95 & 4.81 & 8.23 & - & & & & \\
\hline $\mathrm{MO} \mathrm{Gr}=52$ & 9.22 & 2.34 & 2.83 & 6.52 & 8.89 & 9.37 & 3.18 & 7.55 & 8.14 & - & & & \\
\hline SO $\mathrm{Gr}=55$ & 9.03 & 6.65 & 5.18 & 8.20 & 11.09 & 9.02 & 5.13 & 7.28 & 4.32 & 7.32 & - & & \\
\hline PSMPA $\mathrm{Gr}=110$ & 11.37 & 6.94 & 14.33 & 9.50 & 13.11 & 11.17 & 7.40 & 12.49 & 11.00 & 10.85 & 12.54 & - & \\
\hline $\operatorname{SSS~Gr}=67$ & 13.14 & 5.30 & 5.99 & 9.98 & 9.10 & 8.24 & 9.59 & 8.01 & 9.67 & 6.18 & 7.01 & 10.75 & - \\
\hline $\mathrm{SS} \mathrm{Gr}=36$ & 12.97 & 3.92 & 5.07 & 8.15 & 3.95 & 4.56 & 4.65 & 5.02 & 2.44 & & & 10.07 & 4.89 \\
\hline
\end{tabular}

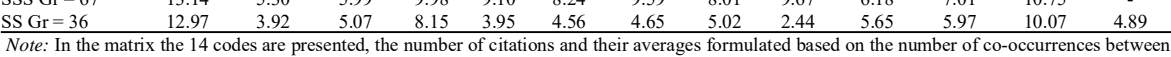
codes according to the incidence within the reading of each one, this method allows to establish an average of the percentage between the two different incidents that are taken as a reference to assess the level of association between the codes that match in the table. $\mathrm{AA}=\mathrm{Areas}$ of action $\mathrm{AISM}=$ Areas that integrate sports management, $\mathrm{OE}=$ Organizational structure, $\mathrm{SMF}=$ Forces of sports management, $\mathrm{MF}=$ Functions of the manager, $\mathrm{SMPA}=$ Management of passive or physical activities, $\mathrm{EM}=$ Management of the environment, $\mathrm{SM}=$ Strategic management, $\mathrm{MM}$ $=$ Management models, $\mathrm{MO}=$ Management objectives, $\mathrm{SO}=$ Sports organizations, $\mathrm{PSMPA}=$ Processes in the management of physical or sports activities, $\mathrm{SSS}=$ Sports services, $\mathrm{SS}=$ Sports system and $\mathrm{Gr}=$ Citations associated with code.

that are contradictory, a matrix was developed that shows the number of co-occurrences between codes and the percentage it represents (see table $3 \mathrm{a}$ and table $3 \mathrm{~b}$ ).

In addition, an average was made between the existing relationship from the interaction of each code with its respective citations that allowed to generate networks and use the modeling technique (see table 4).

\section{Results}

The qualitative analysis obtained through the tables of co-occurrence between codes in Atlas.ti version 8.1. It produced the following most outstanding results:

In the first place, the process in the management of physical or sports activities stands out as the code with the highest co-occurrences over the other codes with a total of 317 (12.23\%; see table 2). While the codes with the highest incidence stand out: the organizational structure with 27 (20.15\%), sports organizations with 29 (15.93\%), strategic management with $31(15.20 \%)$, the sports system with 16 $(15.09 \%)$, the management model with $22(15.07 \%)$, the management objective $22(14.77 \%)$, the management of physical and sports activities $25(14.45 \%)$, and the manager's functions 38 (14.23\%; see table 3$)$.

In the background, the level of impact of the fields of action stands out with a total of 283 (10.92\%; see table 2). The codes with the highest incidence include: the sports system $(18.87 \%)$, sports services $(16.74 \%)$, environmental management (14.68\%), management models (14.38\%), management forces $(13.69 \%))$, the areas of sports management $(13.33 \%)$, the functions of the sports manager $(12.73 \%)$, sports organizations $(10.99 \%)$ and the management process with $(10.73 \%$; see table 3$)$.

In the third instance, the functions of the manager are highlighted with 267 (10.30\%) of co-occurrences (See table 2 ), among the main codes that affect are: the areas of sports management 13 (21.67\%), management forces sports 32 $(13.28 \%)$, sports organizations $24(13.19 \%)$, strategic management 26(12.65), organizational structure 17 (12.69) and fields of action 34 (12.01\%; see tables 3$)$.

There are other codes with significant co-occurrences that should be highlighted from a global analysis such as management forces $241(9.30 \%)$ co-occurrences between codes, sports services with $221(8.53 \%)$ and strategic management $204(7.87 \%)$ on the total of co-occurrences between codes (see table 2).

The results obtained allowed modeling through graphic representations with conceptual models that give clarity about the intention of the work, in addition to responding to the problem raised and complying with the object of study, which resulted in the following products: a scheme the role of the manager of physical and sports activities, the approximate conceptualization of the dynamics of the management of physical or sports activities and lastly, the global intervention model of sports management or physical activities.

The role of the physical and sports activities manager

The results of the analysis-synthesis carried out on the key documents related to the subject, allowed to identify through the coding key functions from a global perspective on the environment that surrounds the physical or sports activities manager, in which elements that define their purpose and the main interactions between them, to define their professionalizing role in the disciplinary context of management.

The codes with the greatest significant contribution through the citations and associations to structure the conceptual scheme as a result of the analysis were the manager's functions with 98 citations representing (11.54\%) and its cooccurrence of $267(10.30 \%)$, the process in the management of physical or sports activities with 110 citations (12.96\%) and a level of co-occurrences of 317 (12.23\%), the fields of action with 110 citations that means $(12.96 \%)$ and an interaction of co-occurrences of $283(10.92 \%)$, another element is the management of physical or sports activities that shows 68 citations in the analysis that represents (8.01\%) with a level of co-occurrences of 173 (6.67\%; see table 2).

One piece of data included in this analysis is that of the sports management areas that from this concept have a strong co-occurrence directly with the relationship that exists between the functions of the physical and sports activities manager represented with 13 incidents that represent the (21.61\%) from the management areas (see tables $3 a$ and $3 b$ ) these components provided relevant information to propose a scheme on the role of the physical and sports activities manager from a general perspective.

The scheme of the role of manager of physical or sports activities considers as a basis the results obtained from the combination of (Table $3 a$ and $3 b$ ) and (table 4 ) product of the previous qualitative analysis in the Atlas.ti 8.1 software. The interpretation presents a central point on which it requires in the first instance to maintain, operate or create plans, projects and programs, with a view to integrating and coordinating the disciplinary areas to support the areas of action, elements that are part of the system of physical or sports activities. In this context, the manager has the responsibility of recognizing the elements required to perform in the different hierarchical 


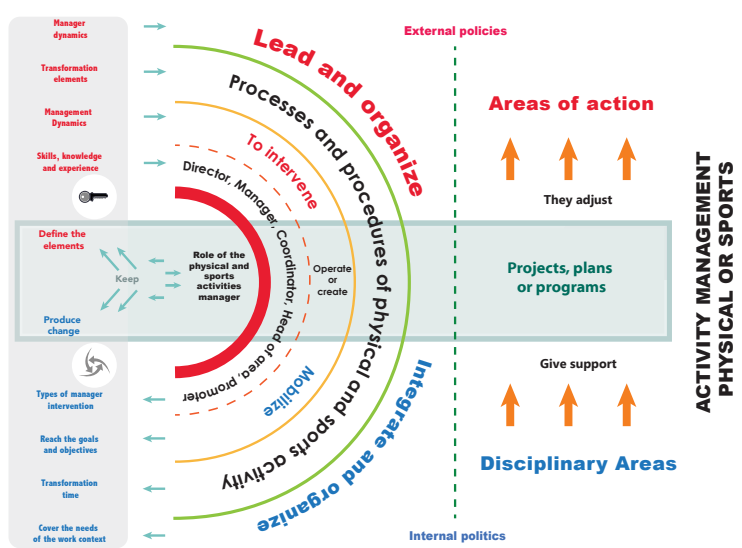

Figure 3. Outline of the role of the manager of physical and sports activities from a general perspective

Note. The scheme is an interpretation product of integrated information from the citations and the interaction among codes, the levels of co-occurrences are respected and the results generated from the analysis-synthesis and the logical history are interpreted in order to apply the modeling technique and thus be able to conceive a scheme that is closer to the reality of the professionalizing context of the manager of physical and sports activities.

levels and triggering the transformative processes to achieve significant changes that contribute to transforming the environment, in line with its dynamics and that of management at all times, to take into account the internal and external policies that allow for efficient and effective management of physical or sports activities (see figure 3). The foregoing coincides with Fernández Puentes \& Vázquez (2019), who agree that the role of the manager falls on the figures of the director, coordinator, area manager, depending on the hierarchical level of the organization, who must have specific objectives to achieve the goals considering that the plans, projects and programs fulfill this purpose

\section{The dynamics of management in physical or sports activities}

The qualitative analysis and the analysis process in the software Atlas.ti 8.1., allowed to develop a network to establish the relationship on the concept identified in the literary review where the dynamics of management is called, the result evidenced 8 codes that interact each and show four different relationships between code-code under the following conditions «is associated with», «is part of», «is the cause of» or «is a» (see figure 4). In this relationship there are very significant interactions, among which the following stand out: the sports system as a field of action with $18.87 \%$, the process of managing physical and sports activities as part of the management of physical and sports activities with $14.45 \%$, the forces of sports management as causes of the management models $10.09 \%$, of sports management or physical activities with $9.83 \%$, of the process of managing physical or sports activities with $8.20 \%$ and of the management objective with $8.05 \%$.

On the other hand, the incidence of the areas of action in their association with the sports management forces stands out $12.68 \%$, the management process with $11.37 \%$, the management models with $10.9 \%$, the objective of the management with $9.22 \%$, and the management of physical and sports activities with $7.45 \%$. These results allow to define with greater precision and understanding the dynamics of the management of physical or sports activities in the professionalizing context determines the essential components that must be considered to achieve better results in the exercise of the management of physical or sports activities (Figure 4).

\section{Global intervention model for the management of physical or sports activities}

This post-structural and postmodern qualitative research on sports and physical activity management resulted in a global intervention model, its basis for support, lies in the complementary literary review, the codification of 38 documents and the fusion of 58 codes. which provided relevant information through the synthesis of 294 citations

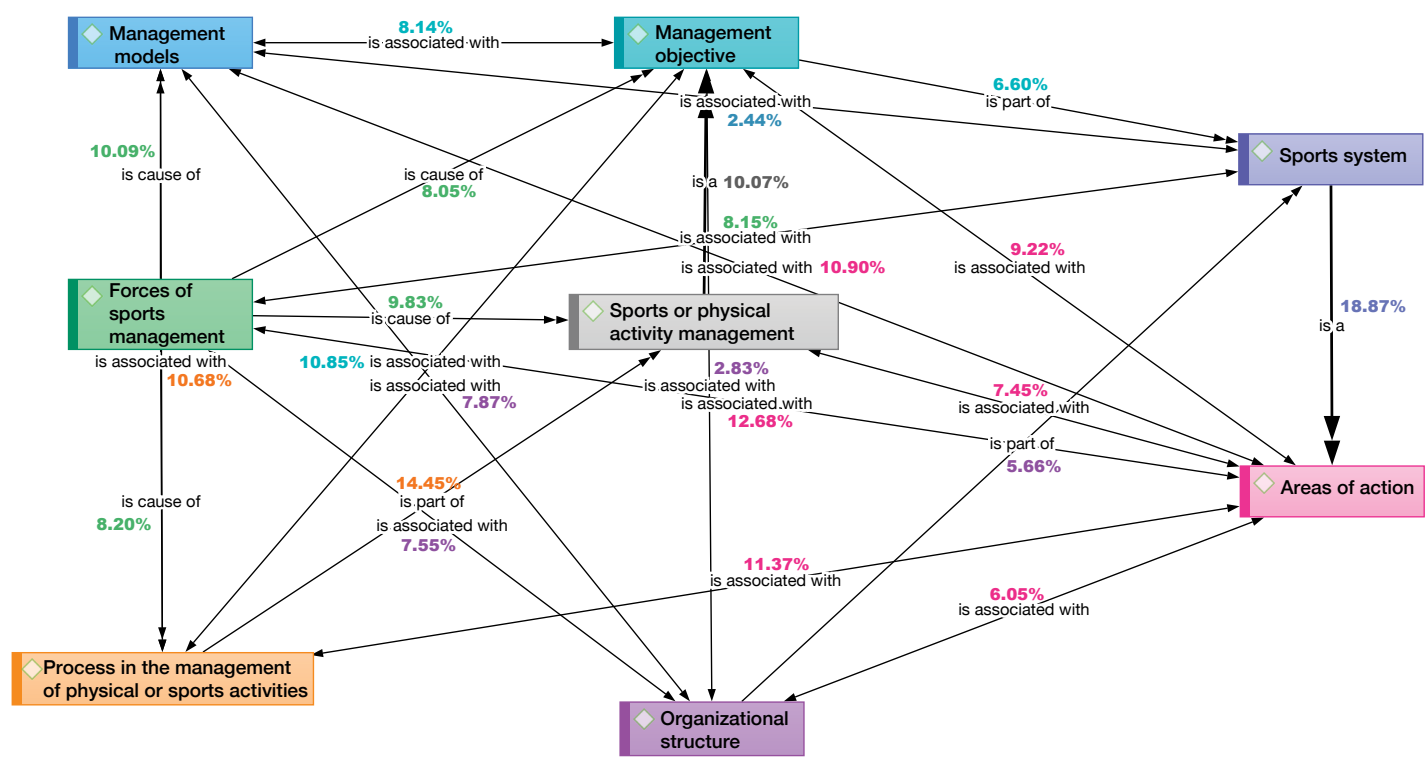

Figure 4. Network of interactions that represents the dynamics of sports management or physical activities.

Note. In the present scheme, eight codes out of the fourteen that are related with the highest incidence among the co-occurrences of the analysis to identify the dynamics of the management are appreciated. The management forces, the areas of action, the management process of physical and sports activities, the organizational structure, the sports system, the management objective, the management of physical or sports activities and the management models must be considered as general components to understand the dynamics of management. It is important to mention that behind this result there are other elements that are associated with each of the codes, which strengthen the result of the qualitative analysis. 


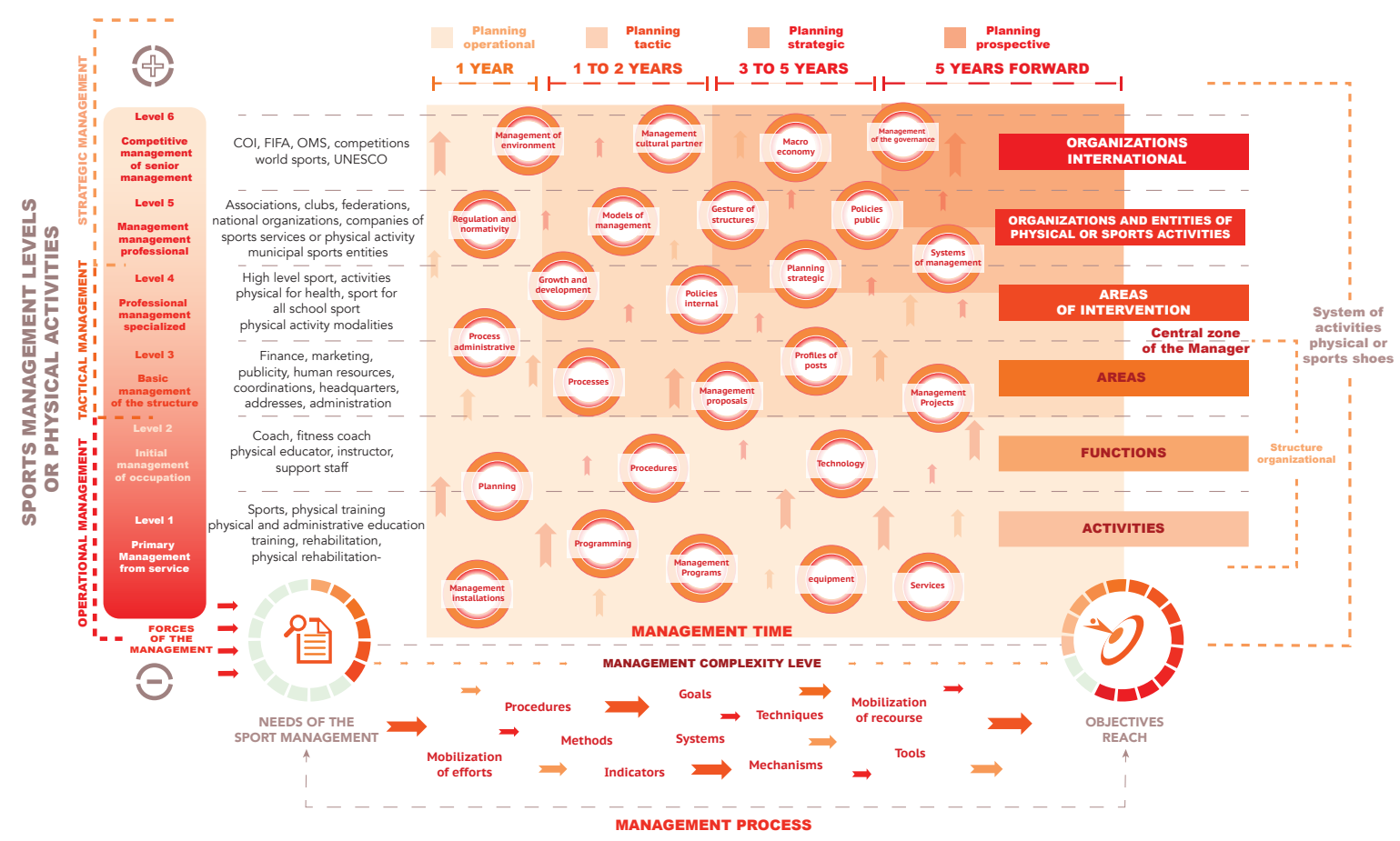

Figure 5. Global intervention model for the management of physical or sports activities

\begin{abstract}
Note. The model represents an approach to the diversified reality of structural patterns, which results from the qualitative analysis of the research, its design starts from a methodology that tries to explain from the simplest to the most complex, which includes basic concepts of technical language commonly used in the management of physical or sports activities. It integrates the different results obtained in the study, in addition to considering elements and components that are articulated among themselves to give it a logical sense in its practical application, which seeks to present a clear idea to meet the object of study and solve the problem arisen.
\end{abstract}

to form 14 consistent codes that affect the conception of the model, in a conceptual scheme where they can be clearly identified (See figure 5). In the analysis there are two codes with a high degree of incidence, one is the process of the management of physical and sports activities with 317 cooccurrences between codes which represents $12.23 \%$, while on the other hand is the areas of action with 283 cooccurrences to account for $10.92 \%$.

The model proposes a global structure, which presents elements, mechanisms, components, approaches, dimensions and means articulated with each other to explain the phenomenon of intervention in sports management or physical activities. Its reading can begin by identifying the management levels, which forces impact, in order to establish the objectives to be achieved, analyze the management process and see examples of the elements and mechanisms that can be considered in order to estimate the time of the management that can be operational, tactical, strategic or prospective within a sports system that determines the areas of action of the management. If we consider a quadrant of the Cartesian plane, in the model scheme the process of managing physical or sports activities operates on the axis of the "X»", the components of the management dynamics are articulated, while the areas of action would be on the axis of the «Y» that make up the system of physical or sports activities, this allows identifying the temporality of the management and the considerations regarding levels and means to be used to achieve the goals or objectives set. This result coincides with that established by Vélez et al., (2018) who affirm that «Knowing the objectives pursued by the members of an organization is a matter of the first order for proper management.» What gives guidelines to define from this approach of the model sports management or physical activities such as attention to the needs of an activity, service or need that requires directing efforts in a coordinated way through appropriate mechanisms and links, which allows mobilizing the different resources in all their dimensions to achieve the objectives or desired ends, in adherence to the processes of time and form in a dynamic of a system, structure or organization in a certain field of action.

\section{Discussions}

The sports system from a global perspective has shown a similar structure in the way of organizing itself for several years, in this sense it coincides with what Rial (2014) mentions. That there is a «requirement for global and transversal management with new management and leadership models, consolidation as a scientific discipline and expansion of the labor market (XXI century)». There is a space to consider the identification and recognition of the structure in relation to the provision of services in physical and sports activities for the population, however, it is necessary to reflect that there is also an opportunity to clarify the intervention from the academic and professional sphere of sports management and its need to merge in a duality with the management of physical activities through a model or scheme that idealizes the field of management of physical and sports activities, to specify the demand for professionals located in these disciplinary fields .

Within the particular role of the sports and physical activities manager, it is highlighted that the central part of the functions lies in the administrative process (planning, organizing, directing and controlling and evaluating) as the key element of management where authors such as Celma (2004), point out that the manager's functions «start from 
the classic orientations (...) suppose an operational approach for the different areas of action and managerial work of the sports manager: conceptual-strategic, planning, organizational, executive and evaluating ...», while Rial (2015), mentions that $« . .$. the great importance of the human factor in the success of the entity's management by fulfilling the functions of: planning, organizing, directing, controlling and evaluating... for current and future times in a very changeable environment ", which includes strategic and adaptive capacity; on the other hand Aguilar and Guerra (2015) in the same sense, point out that in the management of high performance sports the administrative process of planning, organizing, directing and controlling are synergistic pillars, while Bustamante et al. (2019), in their conclusions, mention that the achievement of the objectives is specified through the planning management process, organization, direction and control. Although it is true, the administrative process is a doctrine within the administration, it should be noted that in the management of physical or sports activities and the role of the manager (figure 3), it must take the administrative process as a tool within the different processes modern management due to the fact that its dynamics requires the integration of multiple functions, among which the creation and operation of plans, programs and projects stands out. In addition, it is necessary to consider that the functions are conditioned by different factors such as the type of position, the level of complexity of the management, the different areas of action, the areas that require integration and the different processes and procedures that regulate the functioning of the organization's structure. In the same way, in the global scheme of management intervention (figure 5), it can be clearly evidenced that the administration and its process are integrated as one more element of the dynamics of the management of physical or sports activities within the different systems structural and management levels.

Regarding future lines of research, it should be noted that the analysis of this literary review work encourages the opening of new lines of research mainly related to the dynamics of management, highlighting the forces that mobilize the management of physical or sports activities, the different management processes, time and the relationship it has with the complexity of management. On the other hand, the global intervention model proposes six levels of management that are the object of study for any manager based on the activities and functions he performs, in addition to showing a possible correlation with the types of short, medium- and long-term plans such as possible line of research.

Regarding the practical application, the model has a practical application as an object of analysis and studies in the contents of educational programs of professional training in sports management, it presents basic contents that give clarity to the intervention of the management of physical and sports activities from a global perspective, is a point of reference in this disciplinary area. In addition, it gives rise to new lines of research with basic approaches in the current field of new needs and trends in management.

When it comes to placing it in a context in Latin America, the proposed global intervention model presents a clear structure on the sports system and the practice of physical activities that reflects a perspective of operating in different continents. However, each region presents very particular characteristics in the way of approaching the management of physical and sports activities.

In Latin America, countries such as Brazil, Cuba, Colombia, Ecuador, Guatemala, Nicaragua, Paraguay, Venezuela and Mexico show progress in the intervention of the management of physical and sports activities, facing transformations that start from the recognition of the right to practice and with it the allocation of resources through its constitutional frameworks (Flores 2019)

These public powers strive to solve current problems through public sports policies and the practice of physical activity that positively impact the creation of sports complexes and infrastructure, promotion of practice habits, financing of research, promotion and subsidies in preparation of athletes. However, there are many Latin American countries that do not adopt this practice in their national management model of physical activity and sport (Reyas, 2006; Bazan, 2013).

\section{Conclusions}

The sports or physical activities manager turns out to be a professional in the disciplinary area who is located at different hierarchical levels of an organizational structure, to perform integration and coordination functions of multiple disciplinary areas, with a view to seeking to satisfy the dynamics of the Management, which allows it to mobilize resources in compliance with the plans, programs and projects required by the areas of action, in order to maintain the processes and procedures to produce a change.

Its functions are focused on command skills and capacities corresponding to the hierarchical level in which it is located, in order to create and favor the conditions of practice that the real social environment demands to maintain operational stability and promote favorable change, which it considers new trends.

The size of the organization's structure, the type of position or position according to the hierarchical level, the dynamics and complexity of the management, the natural processes that are required to achieve the goals or objectives, the dynamics of the different areas of action and the integration of the different areas are factors that condition the manager's performance.

For better relevance and operability in management, it is necessary to recognize the dual function of a structured system that demands multiple services, and thus to be able to clearly address a broad panorama that implies the intervention of a professional such as the manager and with it his specialization in the different fields of action.

Regarding the dynamics of sports and physical activity management, the identification of six key components that activate and interact with each other stands out:

1) The mobilizing forces of management referring to those that detonate it in an organizational structure or a structured system of physical or sports activities among which are: Supply and demand, evolution as an agent of change, the economy, the quality, the types of services for the practice of physical or sports activities that are required, competitiveness, sustainability, sustainability, public policies, 
and the socio-cultural structures that demand the practice of the region. In this sense, it is necessary to highlight that the main force that is identified and determined by the others is the provision of the service, because the very essence of physical or sports activities lies in a diversity of services in different areas of action.

2) The management intervention scheme that is mainly composed of three main elements; the planners who visualize the main goals and objectives to achieve in the short, medium or long term, the means that intervene to achieve the objectives and the differentiating elements that are articulated in the system of physical or sports activities.

3) The specific needs of the internal and external environment of the organizations generated by the forces that mobilize the elements that make up the management dynamics, among which are: the types of programs, projects, management models, operational and strategic plans, policies, regulations etc.

4) The guidelines that are part of the organizational structure and satisfy the needs of the management such as: the mission, the vision, the policies, the values in connection with the goals, the objectives, the purpose and the purpose that is pursued.

5) The management process and its respective procedures that determine the temporality of the management according to the degree of complexity of the operation of the elements that comprise it.

6) The time of the management classified by the duration in the short, medium, long term and its prospects, which in turn is conditioned by the complexity of the management and the size of the structure that determines it, since the greater scope towards the greater the internationalization will be the demands of the service and consequently the investment time of the management of the practice needs of physical or sports activities.

A new edge of this model refers to the definition of the six levels of management that go from the simplest to the most complex, which are: 1) The primary management of the service, 2) the initial occupational management, 3) the basic structural management , 4) specialized professional management, 5) professional directive management and 6) competitive management of senior management, which open up new research alternatives to define the functions with greater precision.

The conception shows a complexity based on the deductive and inductive interpretation of the results presented on: the dynamics of management (figure 4), the areas of action, types of management, the means to achieve the objectives, the organizational structure, they are integrated into the scheme that conceptualizes management intervention in the context of physical or sports activities from a global perspective (figure 5). It is worth mentioning that the results highlight three codes that play a very representative role in the model themselves, which are the central axes of its conceptualization, one refers to the areas of action that have a strong impact on the system of physical and sports activities, articulating it to give consistency in a grounded reality, the second is the management process as the central point of the components of the management dynamics, unifying it to give it a functional meaning within the scheme and the third is the role of the manager of physical or sports activities that it is integrated as the executor of the processes and procedures through its multiple functions in the fields of action.

One of the relevant aspects in the context of sports management in Latin America is the creation of the Latin American Sports Management Association (ALGEDE) that was founded on March 6, 2009, which comes to promote the generation and promotion of academic and scientific knowledge as of 2017 with the creation of its magazine on sports management related to end areas. However, management in Latin America presents its own challenges in the decrease of sedentary lifestyle with the increase in physical activation among the population, the consolidation of public policies in sports in most of the countries, the increase in participation in international competitions. , the promotion of scientific research in this disciplinary area and the recognition of physical and sports activity as an industry that detonates the economy of the regions where it is managed efficiently and effectively.

\section{References}

Abreu, J. L. (2014). El Método de la Investigación Research Method. Daena: International Journal of Good Conscience, 9(3), 195-204.

Aguilar, P., \& Guerra, W. (2015). Gerencia del deporte de alto rendimiento en Venezuela. Actualidad Contable Faces, 18(31), $5-29$.

Álvarez L. I. (2017). Factores Determinantes para la Creación de Contextos Sociodeportivos Excelentes. Revista Kronos, 16(2).

Anadón, M. (2008). La investigación llamada «cualitativa»: de la dinámica de su evolución a los innegables logros y los cuestionamientos presentes. Investigación y educación en enfermería, 26(2), 198-211.

Bartoll, Ó. C., \& Domingo, C. H. (2014). El modelo español de deporte en la universidad: fundamentación, descripción y orientaciones para su gestión ética. Retos. Nuevas tendencias en Educación Física, Deporte y Recreación, (26), 128-133.

Barrios, S. A. G. (2018). Cultura gerencial en las organizaciones del deporte profesional: Caso Venezuela. Revista Venezolana de Gerencia, 23(84).

Bazan, N. (2013). Manual director de actividad física y salud de la República Argentina. ISDe Sports Magazine, 5(18).

Blanco, E. (2014). Manual de la organización institucional del deporte ( $2^{\mathrm{a}}$. ed.; Vol. 26). Editorial Paidotribo.

BOE. (2014). III Convenio colectivo estatal de instalaciones deportivas y gimnasios, de 19 de septiembre de 2014 (No 99015105012005). Recuperado de https://www.boe.es/buscar/doc.php?id=BOE-A-2014-9986

Bossio, R., \& Alexander, M. (2006). Política deportiva: factores reales del sistema deportivo. Liberabit, 12(12), 40-47.

Bustamante, G. G., Cruz, M. G., \& Terry, J. M. L. (2019). Fundamentos sobre la gestión de los clubes deportivos formativos en el Ecuador (Original). Revista científica Olimpia, 16(53), 136150.

Camps, A. (2014). La organización del deporte en otros países. En E. Blanco (Ed. De la serie), Manual de la Organización Institucional del deporte (2a . ed., Vol. 26, pp. 127-138). Editorial Paidotribo.

Camy, J., \& Robinson, L. (Eds.). (2007). Managing olympic sport organizations (Vol. 6). Champaign, IL: Human Kinetics.

Carranza, B. D., Sonoda, N. R., Medina, V. M., Lozano, G. A., \& Enriquez, M. M. (2018). Modelos de gestión en la actividad 
